\title{
Tomada de decisão e análise econômico-financeira na implantação de uma estrutiocultura
}

\author{
Drumond Silva, B.L.L. ${ }^{\text {; }}$ Nogueira, A.C. ${ }^{\text {; }}$ Brandalise, N. ${ }^{\text {; }}$ Beserra, V.A. ${ }^{2}$ e Peres, A.A.C. ${ }^{2}$
}

'Departamento de Engenharia de Produção. Universidade Federal Fluminense. Volta Redonda. RJ. Brasil.

2Departamento de Engenharia de Agronegócios. Universidade Federal Fluminense. Volta Redonda. RJ. Brasil.

\section{PALAVRAS CHAVE ADICIONAIS}

Avestruz.

Incubatório.

Método Delphi.

\section{RESUMO}

A criação de avestruz iniciou-se no Brasil, no ano de 1995. Várias informações relativas à produtividade e rentabilidade da atividade precisam ser esclarecidas. Objetivou-se analisar os riscos inerentes a atividade e realizar a viabilidade econômica da estrutiocultura, utilizando incubatório próprio ou terceirizado. A partir das informações obtidas na região Sudeste, entre os anos de 2009 e 2010, em manuais e pesquisas junto aos produtores comerciais que desenvolvem o ciclo completo (incubação, reprodução, cria, recria, engorda e comercialização), profissionais e fornecedores foi possível a caracterização, projeção e os cálculos, considerando uma criação iniciada desde 4 até 40 casais reprodutores, com uma média de produção de 10 filhotes/fêmea/ano. Fluxos de caixa foram construídos caracterizando a atividade para produção de carne, em um horizonte de 10 anos. Foi realizada a composição dos custos de produção e a análise econômica dos criatórios, considerando diferentes formas de incubação dos ovos, permitindo a tomada de decisão frente aos riscos envolvidos. O levantamento dos riscos e os resultados obtidos foram determinados por meio da técnica Delphi, utilizando questionários estruturados aplicados aos especialistas da área de Agronegócios. A ração foi o item de maior participação nos custos. Para ser viável, a criação de avestruz com incubatório próprio, necessita de 36 casais, ao passo que, para a criação que adota o incubatório terceirizado são necessários 27 casais.

\section{Decision making and financial economic analysis for ostrich implantation}

\section{SUMMARY}

\section{ADDITIONAL KEYWORDS}

Ostrich.

Hatchery.

Delphi method.

\section{INFORMACIÓN}

\section{Cronología del artículo.}

Recibido/Received: 07.04.2015

Aceptado/Accepted: 25.01.2016

On-line: 11.06 .2016

Correspondencia a los autores/Contact e-mail:

lelo@metal.eeimvr.uff.br

\section{INTRODUÇÃO}

A estrutiocultura desenvolvida no Brasil é uma atividade pecuária relativamente nova que teve início em 1995 (Suzan e Gameiro, 2007), requerendo muitos cuidados na implantação e exploração da atividade no que se refere ao sistema de produção e manejo dos animais, além dos aspectos mercadológicos de comercialização de animais e produtos. Relatos sobre a criação de avestruz e as características que a envolve em termos de área requerida, produtividade, tempo para recuperação do investimento, aproveitamento de subprodutos como plumas, couro e unhas e rentabilidade econômica são muitas vezes comparados 
erroneamente aos resultados e indicadores obtidos com rebanhos bovinos. Assim, a realização de estudos que promovam o aprofundamento da atividade, a fim de fornecer informações aos interessados na criação, faz-se necessária. Na Nigéria, um estudo realizado por Egbe (2015) sobre a produção e comercialização de avestruzes entrevistou 216 produtores rurais, sendo observado que o maior desafio da atividade está na comercialização da produção, devido à falta de preços compatíveis aos custos de produção. Segundo o autor, à falta de intensificação da atividade e dos sistemas produtivos compromete o atendimento da demanda de mercado, pois se observou que os produtores rurais não aplicam as recomendações prescritas pela assistência técnica e extensão rural e não acompanham os riscos zootécnicos e econômicos da atividade.

O avestruz (Struthio camelus) por se tratar de uma espécie nativa no continente africano pode ser criado em áreas privadas, formando unidades de conservação em grande escala juntamente com a criação de outros animais selvagens. Na Namíbia, essa proposta foi recomendada por Barnes e Jager (1996) que após a avaliação das populações de animais selvagens e as terras privadas disponíveis, durante 20 anos (19721992), observaram que a exploração de uma atividade agropecuária envolvendo animais selvagens para uso e produção sem fins consumistas seria viável financeiramente, gerando emprego e renda, incentivando o turismo da vida selvagem. No Brasil, a criação de avestruzes é recomendada para fins comerciais destinadas ao consumo humano. Segundo Rodrigues e Macedo (2014), a atividade sempre teve um caráter especulativo que a acompanhou na promessa de que os investimentos realizados teriam alta rentabilidade e baixo risco. Porém, entre os anos de 2005 e 2007, a atividade passou por uma grave crise em função de sua operacionalidade, realizada por meio de contratos de compra e venda. Neste período, a principal empresa de operação no Brasil, não conseguiu honrar seus compromissos, promovendo um impacto negativo e descrédito na atividade, após decretar falência. Como em todo investimento, existem inúmeras variáveis que exercem forte influência sobre as decisões dos empreendedores, principalmente aquelas relacionadas aos custos de produção e a viabilidade econômico-financeira. A variação destes pode ser considerada como riscos embutidos no empreendimento, sendo de fundamental importância para o investidor que pretenda ser bem sucedido. Conhecer a composição dos custos de produção é uma solução que permite analisar a melhor forma de se investir, evitando assim o amadorismo e um possível fracasso do empreendedor a fim de reduzir as incertezas (Nogueira et al., 2012). A estrutiocultura brasileira, após a crise precisou se reestruturar, devido ao descrédito de criadores e consumidores. A partir daí, a atividade apresentou forte tendência em atuar de forma verticalizada, pois um dos fatores responsáveis para o retorno ao crescimento foi o fim da venda de coprodutos da ave, pois se observou o esgotamento da fase de formação de plantel nacional (Rodrigues e Macedo, 2014).

O efetivo do rebanho brasileiro passou de 120000 aves (2003) para 430000 aves (2007) distribuídas em 3200 criatórios (Suzan e Gameiro, 2007). Os maiores estados produtores, segundo Muniz (2006) foram: Goiás (110 000 aves), São Paulo (90 000 aves) e Bahia (60 000 aves). O Brasil apresentou o segundo maior rebanho do mundo com um efetivo estimado de 450.220 aves, em 2540 criatórios, ficando atrás apenas da África do Sul, com um rebanho estimado em 600.000 aves (ACAB, 2006). O abate realizado em 2007 foi de 30071 aves, com uma produção total de 901 toneladas de carne (Silva, 2008). Com a crise do setor, registrou-se em 2010 um abate de 5953 aves, inspecionadas pelo Serviço de Inspeção Federal e a atividade chegou ao ponto mínimo com prospecção de crescimento para os próximos anos entre 10 e $20 \%$ no total de aves abatidas (Avicultura Industrial, 2011).

A estrutiocultura é considerada investimento de longo prazo e tem ainda um pequeno nicho de mercado para a comercialização da carne. Por apresentar indicadores zootécnicos de produção e econômicos atrativos, bem como características de adaptabilidade e rusticidade dos animais, a estrutiocultura apresenta-se como uma alternativa de investimento. A potencialidade do mercado consumidor, segundo Rodrigues e Macedo (2014), pode ser destacada por diversos pontos: como o crescente aumento da população mundial, o que torna imprescindível a busca por alimentos alternativos para suprir a demanda, mudanças estruturais, por conta da nova realidade socioeconômica interna e externa, que provocaram a reestruturação nas cadeias produtivas tradicionais e a criação de novas barreiras sanitárias causadas por diversas doenças que prejudicaram o mercado da carne vermelha e de frango.

Objetivou-se identificar os principais riscos inerentes a criação de avestruz, por meio do método Delphi e realizar a análise econômico-financeira da atividade para a produção de carne, em duas modalidades de exploração: incubação de ovos realizada na fazenda ou incubação de ovos terceirizada.

\section{MATERIAL E MÉTODOS}

O trabalho foi realizado junto ao grupo de pesquisa do CNPq: Planejamento e gestão em sistemas de produção agropecuária, da Universidade Federal Fluminense, em Volta Redonda, RJ, entre os anos de 2009 e 2010. Utilizando-se dos levantamentos e resultados obtidos em junho de 2009 no trabalho de Nogueira (2009), sobre a viabilidade econômico-financeira da criação de avestruz, propuseram-se estudos sobre a tomada de decisão de investimento e a determinação dos riscos envolvidos na atividade, de acordo com Harris e Raviv (1996). A cotação média do dólar comercial para venda, no mês de junho de 2009 foi de US\$ 1,00= R\$ 1,958 (ACSP, 2015).

Para a caracterização do sistema de criação e a compreensão das dificuldades existentes na atividade desenvolvida no Brasil, utilizou-se do levantamento bibliográfico de livros e artigos científicos, além da realização de visitas técnicas em criatórios, na região sudeste brasileira. A partir daí, levantou-se os investimentos necessários para iniciar a atividade e os custos envolvidos, através de consultas aos fornecedores de máquinas, equipamentos, insumos em geral e a mão- 
de-obra. Foram levantados os dados de desempenho zootécnico e os indicadores de produção recomendados para a criação, bem como as tendências do mercado brasileiro, considerando as opiniões de especialistas, oportunidades do mercado e parcerias viáveis. De posse das informações inerentes a exploração comercial de avestruz, procedeu-se o planejamento zootécnico e econômico, englobando as variáveis existentes a fim de determinar a viabilidade técnica e econômica.

Na definição das receitas e despesas envolvidas na atividade, procedeu-se a caracterização e identificação do capital financeiro necessário para o investimento inicial, compra de animais, contratação de mão de obra e os custos administrativos. No investimento inicial, consideraram-se os custos envolvidos na construção de piquetes e creches, formação de pastagens cultivadas, construção das salas para incubação de ovos, bem como as máquinas e equipamentos necessários para a atividade (incubadoras, maternidades, aparelho de ovoscopia, entre outros,... ), instalações e benfeitorias, além dos custos com a legalização do empreendimento (licenças, alvarás, regularização,... ). A compra de animais (casal) considerou a aquisição de reprodutores e matrizes em idade reprodutiva e as possíveis perdas ao longo da criação. Para definição das receitas obtidas com a atividade, considerou-se a venda do animal pronto para o abate, com peso corporal de $110 \mathrm{~kg} \mathrm{e}$, a venda de $20 \%$ dos ovos inférteis destinados ao artesanato.

Os indicadores zootécnicos definidos para a construção dos ciclos de produção e o fluxo da caixa foram: total de 20 ovos (primeira postura) e 40 ovos (segunda postura em diante) produzidos por fêmea/ano, $60 \%$ de eclodibilidade de pintinhos, $45 \%$ de sobrevivência de filhotes após três meses de idade, o que totalizou entre 5 e $6\left(1^{\circ}\right.$ ano), 10 e 11 ( $2^{\circ}$ ano, em diante) animais produzidos/fêmea/ano. Com a evolução do rebanho definida, determinou-se o consumo de ração necessário para manutenção dos animais e custeio. No abate, o rendimento médio da carcaça, foi na ordem de $52 \%$. Para simulação dos dados, considerou-se os indicadores zootécnicos propostos por Suzan e Gameiro (2007), com os casais apresentando uma longevidade reprodutiva de três anos a 40 anos de idade e uma produção média anual de 15 filhotes / fêmea, com tempo de abate de 12 meses.

Em relação às despesas com mão de obra, estimaram-se os gastos necessários com a contratação de funcionários para o manejo de animais, a assistência técnica com médico veterinário e o deslocamento, treinamento de funcionários, entre outros,...

Os custos administrativos consideraram a manutenção e reparos necessários aos imóveis, instalações, benfeitorias, piquetes, cercas e equipamentos em geral, além de gastos com energia elétrica e impostos.

Na realização da análise dos dados foram construídos diferentes fluxos de caixa, utilizando-se de planilhas eletrônicas do MS-Excel ${ }^{\circledR}$ para computar todas as receitas e as despesas incorridas na atividade para os cenários estudados, considerando as peculiaridades de cada sistema produtivo. A análise econômico-financeira para determinação do indicador econômico de ren- tabilidade valor presente líquido (VPL) e o tempo de recuperação do capital investido (payback) seguiu a metodologia proposta por Blank e Tarquin (2008).

Os cálculos realizados consideraram inicialmente, a aquisição de 4 casais de avestruzes, em estágio reprodutivo, com potencial genético para produção de 40 ovos/ano. Para a primeira postura de novos casais, considerou-se uma produção inicial de 20 ovos/ano ( $1^{\circ}$ ano) e, nos anos seguintes a produção passou a 40 ovos/fêmea. A receita obtida foi calculada, considerando a venda da ave terminada para o abate com peso corporal de $110 \mathrm{~kg}$, descontando-se $10 \mathrm{~kg}$ de peso corporal referente ao manejo, transporte até o abatedouro e o tratamento dos animais, na fase de pré-abate. Os cenários de comercialização das aves (preços de abate) foram estudados nos estados de Minas Gerais, São Paulo e Rio de Janeiro, considerados um grande potencial consumidor da carne. No estado de Minas Gerais, pagou-se $\mathrm{R} \$ 4,50 / \mathrm{kg}$ de peso corporal, gerando uma receita de $\mathrm{R} \$ 450,00$ / ave. Em São Paulo, os preços pagos foram de $R \$ 7,00, R \$ 8,00$ e $R \$ 9,00 / \mathrm{kg}$ de carne produzida, em função do rendimento de carcaça, após $\mathrm{o}$ abate, respectivamente, para rendimentos menores que $48 \mathrm{~kg}$, entre $48 \mathrm{~kg}$ e $52 \mathrm{~kg}$ e rendimentos maiores que $52 \mathrm{~kg}$ de carne. No estado do Rio de Janeiro, o valor negociado para o preço do animal foi de $R \$ 10,00 / \mathrm{kg}$ de peso corporal. Considerou-se ainda, o recebimento de $R \$ 5,00$ /ovo infértil destinados ao artesanato.

A capacidade e os custos da incubadora foram determinados em função dos indicadores zootécnicos, sendo necessária uma incubadora com capacidade para incubação de 180 ovos, já desconsiderados as perdas dos ovos inférteis e mortalidade de filhotes. Foram considerados, os custos para instalação da incubadora, o transporte do equipamento, a hospedagem e alimentação do funcionário responsável, na condição da incubadora própria. Para a condição da incubadora terceirizada, estimou-se o custo $(R \$ 45,00)$ de transporte até o incubatório e o pagamento de aluguel por ovo incubado, na ordem de R $\$ 0,42$.

Outros custos envolvidos na atividade foram a assistência veterinária equivalente a um salário mínimo ( $R \$ 465,00)$ por dia contratado, adicionado ao custo com deslocamento ( $\mathrm{R} \$ 1,00 / \mathrm{km}$ rodado) com visitas mensais, durante o primeiro ano e, trimestralmente, a partir do segundo ano. Para a mão de obra contratada, considerou-se um funcionário responsável pelos piquetes de reprodutores, um funcionário para a creche e preparo dos animais destinados ao abate e um funcionário responsável pela incubadora (na condição que adota incubatório próprio) e demais serviços, sendo estes remunerados pelo valor de um salário mínimo mensal, acrescidos de 10,62\% de encargos trabalhistas.

Para implantação da atividade, considerou-se o pagamento de $\mathrm{R} \$ 20,00$ / dia para o pagamento de mão de obra temporária destinada à construção de piquetes e $R \$ 60,00 /$ dia para construção das edificações, e ainda, como investimento a compra de máquinas e equipamentos e aquisição de animais, bem como a depreciação destes, de acordo com a vida útil.

Os custos operacionais foram aqueles envolvidos na incubação dos ovos, na compra de ração balan- 
ceada, nos volumosos fornecidos, nos medicamentos, exames, despesas com energia elétrica, pagamento de impostos como pessoa jurídica, pelo simples nacional, de acordo com a receita bruta obtida com a atividade, imposto territorial rural (ITR) da propriedade e FGTS e INSS da mão de obra contratada e despesas com material de escritório, gráfica, entre outros.

Definiu-se o ciclo produtivo realizado nas condições de incubatório próprio e terceirizado, mediante as características gerais da atividade, sendo definidas as categorias e os itens que as compõem, como: investimento inicial, aquisição de animais, mão-de-obra e custos administrativos, de acordo com as peculiaridades de cada sistema produtivo. Para a caracterização da criação e a construção dos fluxos de caixa, nos sistemas de produção, o manejo adotado foi separado por lotes, considerando a idade e o peso vivo dos animais. Para Giannoni (2002), na criação de avestruz para abate com incubação própria, exige-se em termos de infraestrutura, mão-de-obra especializada e manejo correto dos ovos, ao passo que, na incubação terceirizada, os custos envolvidos na incubação dos ovos passam a ser um único item dos custos de produção.

Utilizou-se o método Delphi, proposto por Olaf Helmer e Norman Dalker (Estes e Kuespert, 1976) para determinar os principais riscos envolvidos na criação e a partir daí, analisar as informações obtidas, mediante aplicação de questionários específicos a profissionais que atuam no setor agropecuário, o que permitiu descobrir as opiniões de especialistas, sem que haja interpretação pessoal entre os mesmos. Esta técnica permitiu preservar o anonimato dos respondentes, a representação estatística dos resultados e a opinião de respostas do grupo para reavaliação nas rodadas subsequentes (Martino, 1993). Posteriormente, inseriramse os riscos determinados no fluxo de caixa proposto por Nogueira (2009), sendo construídos novos fluxos de caixa nos cenários definidos pelo estudo.

O método Delphi permite descobrir as opiniões de especialistas, sem que haja interpretação pessoal entre os mesmos, através da realização de uma série de questionários. O princípio do método é intuitivo e interativo, implicando na constituição de um grupo de especialistas em determinada área do conhecimento, que respondem a uma série de questões. Os resultados dessa primeira fase foram analisados e a síntese dos resultados comunicada aos membros do grupo que, após tomarem conhecimento, respondem novamente. As interações se sucedem desta maneira até que um consenso seja obtido. As interações do método são denominadas de rounds e se distinguem por três características básicas: anonimato, interação com a opinião controlada e respostas estatísticas do grupo. Na realização do método Delphi, os trabalhos seguiram a proposta apresentada por Skulmoski et al. (2007), com três etapas para realização (figura 1). Na primeira etapa, os questionários foram elaborados e os respondentes identificados sendo encaminhados a eles. Na segunda etapa depois de respondidos, os questionários foram analisados e resumiram-se as principais conclusões por parte da equipe que liderou o método, sendo devolvidos aos respondentes, para que os mesmos tivessem a oportunidade de rever as respostas e alterá-las, se fosse necessário. Em caso, da resposta variar muito em relação às demais do grupo, o autor deveria justificar a diferença de opinião. Na terceira e última etapa, procedeu-se a análise dos dados e foi apresentado o resumo, promovendo a revisão das respostas até atingir o consenso entre todos os especialistas.

Para aplicação do método aos respondentes foi necessário realizar todo o levantamento sobre a criação no Brasil, bem como a identificação dos instrumentos aplicados a tomada de decisão em investimento e aos riscos. A partir daí, planejou-se e organizaram-se todos os riscos considerados importantes na atividade, sendo estes classificados em riscos internos e riscos externos (tabela I). Elaborou-se um mapa de riscos identificados inerentes a estrutiocultura, com base na literatura consultada para orientar a elaboração do questionário a ser aplicado aos respondentes (especialistas) que atuam na área de Agronegócios, a fim de se obter o risco total (fi-
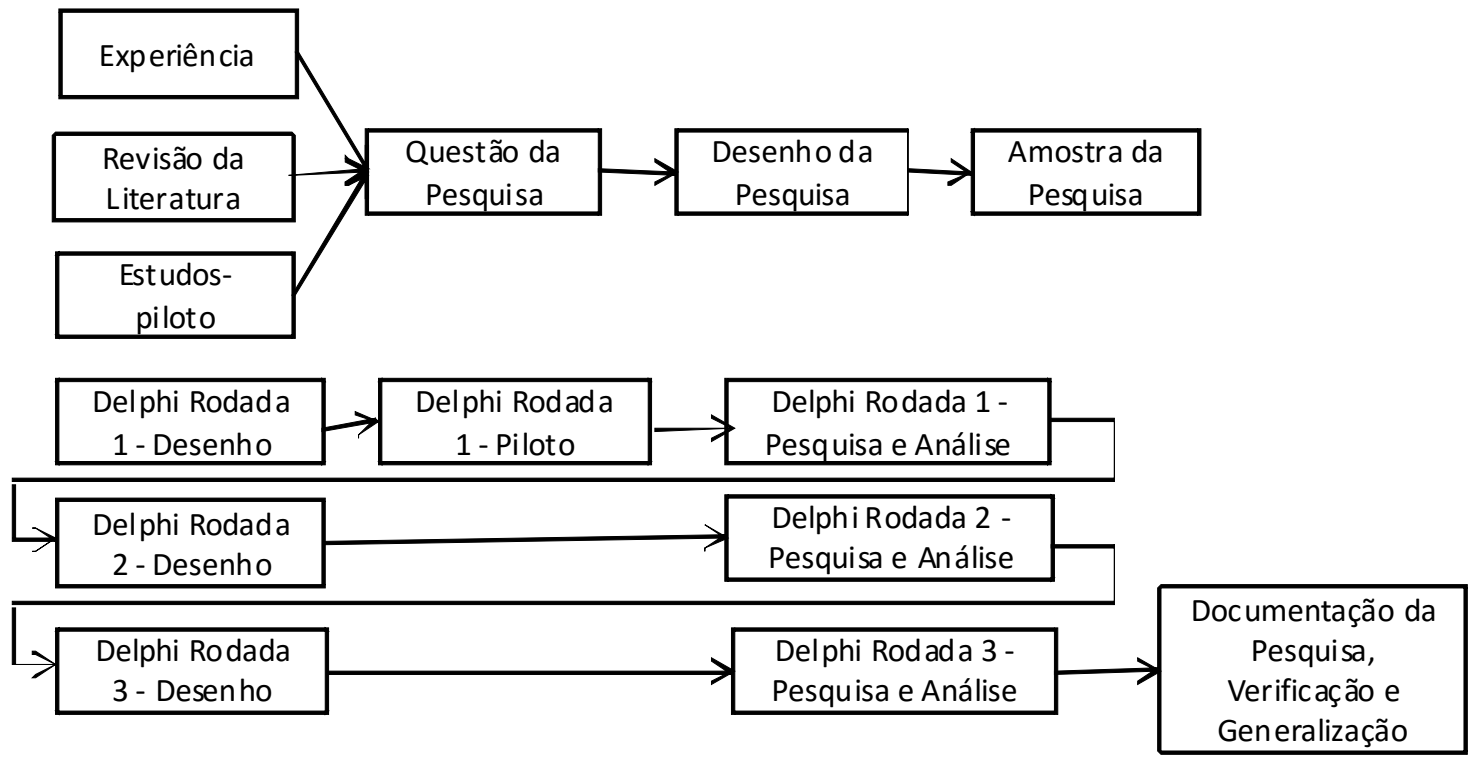

Figura 1. Esquematização do método Delphi em três etapas (Skulmoski et al., 2007) (Delphi method layout in three steps). 
Tabela I. Principais riscos que influenciaram na criação de avestruzes (Main risks that influence the ostrich farm).

\begin{tabular}{|c|c|c|c|c|c|}
\hline Ambiente & Tipo & \multicolumn{2}{|l|}{ Escolha } & Descrição & Exemplo \\
\hline \multirow{5}{*}{ Interno } & Empreendimento & \multicolumn{2}{|c|}{$\begin{array}{l}\text { Fornecedor } \\
\text { Matéria prima } \\
\text { Equipamentos }\end{array}$} & $\begin{array}{l}\text { Relacionados às escol- } \\
\text { has administrativas da } \\
\text { gerência da empresa }\end{array}$ & $\begin{array}{l}\text { Não cumprimento dos prazos dos } \\
\text { pedidos } \\
\text { Baixa qualidade da ração } \\
\text { Câmara frigorífica inadequada }\end{array}$ \\
\hline & Liquidez & & & $\begin{array}{l}\text { Falta de mercado con- } \\
\text { sumidor }\end{array}$ & $\begin{array}{l}\text { Elevado estoque de carne, devido a } \\
\text { preço e hábito alimentar }\end{array}$ \\
\hline & \multirow{3}{*}{ Operacional } & $\begin{array}{l}\text { Humano ou } \\
\text { Pessoas }\end{array}$ & $\begin{array}{l}\text { Erro não intencional } \\
\text { Qualificação } \\
\text { Erro intencional }\end{array}$ & \multirow{4}{*}{$\begin{array}{l}\text { Erros humanos ou des- } \\
\text { falques }\end{array}$} & Desplume feito de forma incorreta \\
\hline & & Processo & $\begin{array}{l}\text { Transação } \\
\text { Conformidade } \\
\text { Controle } \\
\end{array}$ & & $\begin{array}{l}\text { Falta de controle no processo de incu- } \\
\text { bação causando morte de pintinhos }\end{array}$ \\
\hline & & \multicolumn{2}{|l|}{ Tecnológico } & & Sobrecarga elétrica na câmara frigorífica \\
\hline \multirow{8}{*}{ Externo } & Operacional & $\begin{array}{l}\text { Estratégia in } \\
\text { aos fatores a }\end{array}$ & $\begin{array}{l}\text { propriada em respostas } \\
\text { nbientais }\end{array}$ & & $\begin{array}{l}\text { Demissão de funcionários devido ao } \\
\text { aumento de tributos, impossibilitando o } \\
\text { cumprimento de contratos no prazo }\end{array}$ \\
\hline & \multirow[b]{2}{*}{ Negócio } & \multicolumn{2}{|c|}{ Retração da demanda } & \multirow{2}{*}{$\begin{array}{l}\text { Relacionados às ativida- } \\
\text { des da empresa e afe- } \\
\text { tam todas as empresas } \\
\text { do ramo, concorrentes e } \\
\text { próximos }\end{array}$} & $\begin{array}{l}\text { Diminuição do número de consumidores } \\
\text { de carne }\end{array}$ \\
\hline & & \multicolumn{2}{|c|}{ Escassez de matéria prima } & & Escassez de ração \\
\hline & Mercado & & & Mudança no preço & Aumento no preço da ração e insumos \\
\hline & Crédito & & & Contraparte não paga & Cliente não cumpre com a dívida \\
\hline & \multirow{3}{*}{ Legal } & Legislação & & \multirow{3}{*}{$\begin{array}{l}\text { Incerteza dos retornos } \\
\text { bancários, caso os } \\
\text { contratos não possam } \\
\text { ser amparados, por } \\
\text { insuficiência de docu- } \\
\text { mentos, insolvência ou } \\
\text { ilegalidade }\end{array}$} & $\begin{array}{l}\text { Reclassificação do animal para catego- } \\
\text { ria de exótico }\end{array}$ \\
\hline & & Tributário & & & Criação de novo tributo para a atividade \\
\hline & & Contrato & & & $\begin{array}{l}\text { Não execução de garantias, requerendo } \\
\text { o acionamento jurídico }\end{array}$ \\
\hline
\end{tabular}

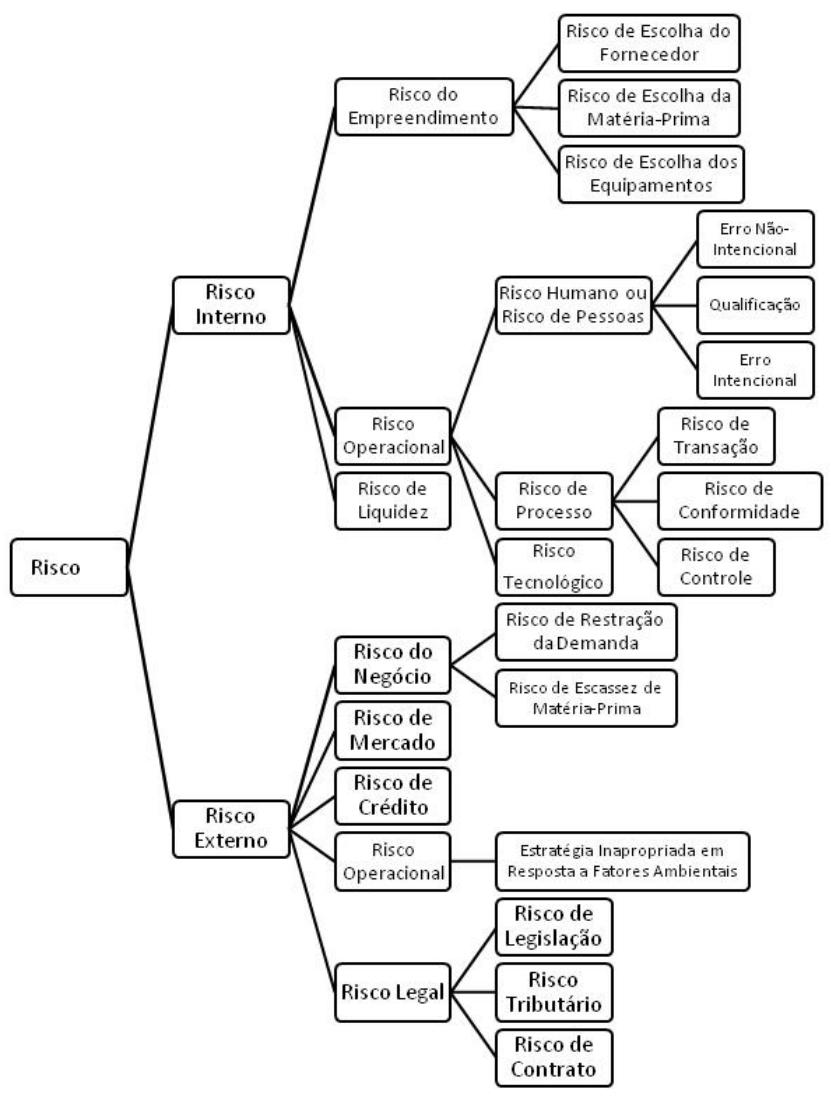

Figura 2. Mapa de riscos em uma criação de avestruzes (Risk map for the ostrich farm). gura 2). O questionário colheu os dados e informações, através de uma técnica de ajuste de risco, seja possível encontrar a taxa de retorno exigida ajustada ao risco. O questionário contou com a seguinte problemática: considerando uma criação de avestruzes, qual a probabilidade de ocorrência dos seguintes riscos? Expresse a intensidade com que se acredita na concretização de cada um dos riscos apresentados. O questionário contemplou 19 tipos de riscos que foram avaliados pelos profissionais da área, sendo elaborado em uma de planilha do MS-Excel ${ }^{\circledR}$ com uma barra de rolagem, que apresentou um intervalo entre 0 e 100, e foi ajustada pelo profissional de acordo com a sua crença de maior ou menor probabilidade de ocorrência do risco em questão (figura 3). Antes de aplicar o questionário aos respondentes foi realizado um teste para avaliar sua eficiência e eventuais falhas, com supervisão de um especialista. $\mathrm{O}$ teste foi considerado satisfatório e aplicável.

Na aplicação dos questionários foram selecionados 30 respondentes atuantes na área de Agronegócios. Destes, somente nove afirmaram ter conhecimentos que auxiliassem na realização do levantamento e análise de dados inerentes ao risco da atividade. Procedeu-se então, a aplicação do questionário de forma individual, espontânea, sem julgamento de cada questão, finalizando a primeira rodada de avaliação. Para a execução da segunda rodada, aplicou-se o mesmo questionário aos mesmos respondentes, porém, nesta etapa cada respondente teve acesso às respostas da pri- 


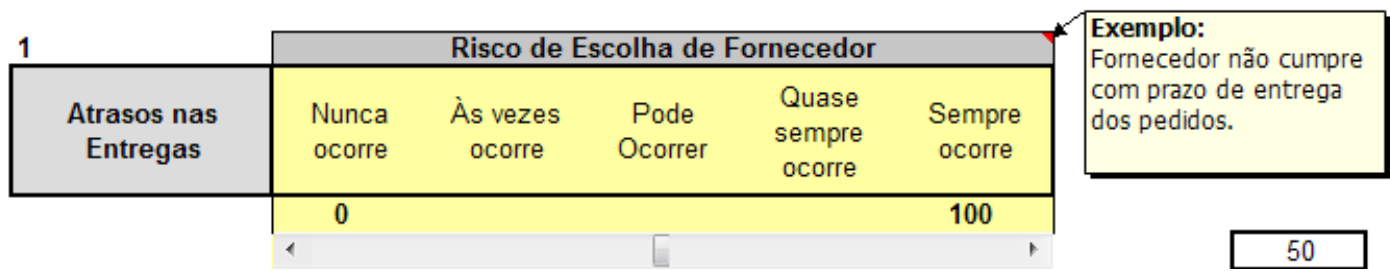

Figura 3. Modelo de questionário aplicado aos respondentes (Questionnaire model applied to respondents).

Tabela II. Tipo de risco, média e desvio-padrão e a redução ou aumento entre as respostas dos respondentes (Risk type, average, standard deviation and percentage difference between the answers of respondents).

\begin{tabular}{|c|c|c|c|}
\hline \multirow{2}{*}{ Tipo de risco } & \multicolumn{2}{|c|}{ Média e desvio-padrão (\%) } & \multirow{2}{*}{$\begin{array}{c}\text { Diferença } \\
(\%)\end{array}$} \\
\hline & $1^{a}$ rodada & $2^{\mathrm{a}}$ rodada & \\
\hline Escolha do fornecedor & $45 \pm 8,45$ & $42 \pm 9,81$ & $+16,09$ \\
\hline Escolha da matéria prima & $31 \pm 13,35$ & $29 \pm 10,56$ & $-20,90$ \\
\hline Escolha dos equipamentos & $24 \pm 19,97$ & $23 \pm 13,90$ & $-30,40$ \\
\hline Liquidez & $42 \pm 13,83$ & $42 \pm 9,82$ & $-28,99$ \\
\hline Humano ou de pessoas - Não intencional & $38 \pm 12,66$ & $44 \pm 12,66$ & 0,00 \\
\hline Humano ou de pessoas - Qualificação & $14 \pm 27,63$ & $16 \pm 13,82$ & $-49,98$ \\
\hline Humano ou de pessoas - Intencional & $26 \pm 10,16$ & $26 \pm 8,27$ & $-18,60$ \\
\hline Transação & $43 \pm 11,68$ & $45 \pm 11,68$ & 0,00 \\
\hline Conformidade & $31 \pm 23,65$ & $32 \pm 21,48$ & $-9,18$ \\
\hline Controle & $50 \pm 18,47$ & $46 \pm 16,72$ & $-9,47$ \\
\hline Tecnológico & $40 \pm 14,27$ & $43 \pm 9,52$ & $-33,29$ \\
\hline Estratégia inapropriada em resposta a fatores ambientais & $40 \pm 21,11$ & $47 \pm 18,68$ & $-11,51$ \\
\hline Retração da demanda & $16 \pm 21,55$ & $19 \pm 18,46$ & $-14,34$ \\
\hline Escassez de matéria prima & $61 \pm 15,19$ & $59 \pm 12,12$ & $-20,21$ \\
\hline Mercado & $55 \pm 14,04$ & $52 \pm 12,59$ & $-10,33$ \\
\hline Crédito & $36 \pm 13,81$ & $38 \pm 10,98$ & $-20,49$ \\
\hline Legislação & $18 \pm 23,89$ & $20 \pm 22,90$ & $-4,14$ \\
\hline Tributário & $18 \pm 19,01$ & $18 \pm 19,01$ & 0,00 \\
\hline Contrato & $37 \pm 17,12$ & $36 \pm 14,05$ & $-17,93$ \\
\hline
\end{tabular}

Tabela III. Risco total e desvio-padrão do risco total das respostas dos especialistas nas duas rodadas de aplicação dos questionários (Total risk and standard deviation of the total risk for the responses of experts in both the questionnaires application rounds).

\begin{tabular}{lccc}
\hline Fonte de variação & $1^{\text {a }}$ rodada & $2^{\text {a }}$ rodada & Diferença $(\%)$ \\
\hline Risco total & 0,34 & 0,35 & $+2,94$ \\
Desvio-padrão & 0,09 & 0,06 & $-33,33$ \\
\hline
\end{tabular}

meira rodada dos demais, bem como o valor da média, do mínimo e do máximo risco para cada questão. Por não ser possível, obter os possíveis riscos da atividade e dados históricos na literatura justificou-se a aplicação do método Delphi, proposto por Skulmoski et al. (2007) para que fosse possível a obtenção do risco total associado a criação de avestruz. Para o cálculo do risco total foi considerado a média geométrica das opiniões respostas dos questionários, conforme a fórmula abaixo:

$$
\operatorname{RISCO}_{\text {total }}=\left(a_{1} \times a_{2} \times \ldots \times a_{n}\right)\left(\frac{1}{n}\right)
$$

Os resultados obtidos foram analisados graficamente para facilitar a visualização da viabilidade ou não da implantação em relação à quantidade de casais reprodutores necessários para iniciar a criação. A análise financeira realizada foi projetada para um horizonte de 10 anos e, considerou desde a aquisição de 4 até 40 casais reprodutores.

\section{RESULTADOS E DISCUSSÃO}

Os dados obtidos por meio da aplicação dos questionários foram analisados e tiveram as médias e os desvios padrões observados para cada tipo de risco, sendo avaliada a ocorrência de redução ou aumento entre as rodadas realizadas, buscando o consenso entre os respondentes (tabela II). Para avaliação dos riscos foi observada uma redução no desvio padrão, na ordem de aproximadamente $30 \%$, entre a primeira e a segunda rodada de aplicação dos questionários, passando de 0,09 para 0,06 , o que demonstrou que as respostas apresentadas pelos especialistas apresentaram maior similaridade e buscaram um consenso entre eles (tabela III). Do total de 19 fatores de riscos considerados relevantes para a exploração da estrutiocultura, 15 destes apresentaram redução no desvio-padrão entres as rodadas realizadas. Esse resultado demonstrou que houve maior uniformidade entre as respostas dos especialistas, após a segunda rodada de aplicação. Somente o risco do fornecedor apresentou aumento no desviopadrão, o que refletiu na diferença entre opiniões dos especialistas. Para o risco humano ou pessoas por erro 
intencional, risco de transação e risco tributário, a opinião entre os especialistas se mantiveram estáveis, sem divergências. O método Delphi (Skulmoski et al., 2007), adota o uso da taxa de risco e considera o equivalente de certeza para calcular, a partir da taxa livre de risco e da taxa ajustada ao risco, as respostas apresentadas pelos respondentes (especialistas), de forma a uniformizar e inferir o grau de importância dos riscos associados a criação. Observou-se um maior consenso entre as respostas dos especialistas sobre o risco total na segunda rodada de aplicação dos questionários. No método Delphi, a cada rodada, procurou-se a uniformização sobre os riscos levantados e relacionados nos questionários, isto é, o objetivo principal foi a busca do consenso entre os respondentes sobre determinado assunto ou questionamento. Em termos estatísticos, buscou-se atingir uma média aritmética associada ao baixo valor para os desvios padrão, pois assim os resultados obtidos indicaram a ausência de variabilidade entre os respondentes. Neste trabalho, foi observado que entre as rodadas de avaliação houve uma redução em termos estatísticos nas opiniões dos respondentes, por meio da redução do desvio padrão, demonstrando que o método Delphi foi eficiente para se alcançar a um consenso entre os respondentes e, permitir que as análises econômicas realizadas refletissem sobre o comportamento da exploração da atividade, de acordo com a realidade na região estudada, sendo possível a realização da composição dos custos de produção e a determinação dos demais indicadores econômicofinanceiros que auxiliaram na tomada de decisão.

Foi observado entre os respondentes que a escassez de matéria prima para a exploração da atividade e os aspectos mercadológicos para comercialização dos produtos produzidos foram os riscos considerados de maior relevância (tabela II). O maior gerenciamento e controle das decisões na gestão da atividade sobre estes riscos permitem ao produtor obter êxito na criação. Essa observação demonstrou que o empreendimento está mais vulnerável aos fatores externos do que aqueles classificados como internos, no que tange a exploração da atividade. No risco escassez de matéria, entende-se que a preocupação dos respondentes envolveu desde a oferta de insumos para o balanceamento de rações, como o preço praticado na comercialização destes e, por se tratarem de alimentos classificados como commodities, o milho, a soja,... os preços praticados na comercialização dependem da safra produzida e do comportamento da economia mundial, bem como dos demais componentes que integram o balanceamento das rações oferecidas aos animais. $\mathrm{O}$ risco de mercado é outra preocupação observada pelos respondentes, pois a atividade desenvolvida se trata de uma cultura de pouco conhecimento da população e, os produtos ofertados (carne) não fazem parte do cardápio dos consumidores brasileiros e não apresentam preços acessíveis. Neste caso, o produtor se não estiver integrado a um frigorífico que auxilie na comercialização da carne, pode ficar com os animais na propriedade, sem conseguir a comercialização a preços compatíveis ao consumidor e que sejam suficientes para cobrir os custos de produção da atividade, aumentando o tempo de permanência dos animais na propriedade, aumen- tando os custos de produção e reduzindo a margem de lucro do produtor.

Os riscos classificados como humano que envolve a qualificação de funcionários, a retração de da demanda pelo produto e aqueles que envolveram a legislação e a tributação da atividade (tabela II) foram considerados pelos respondentes como sendo os riscos de menor importância à atividade. Os riscos mencionados realmente não impedem ou inviabilizam a atividade, por se tratarem de riscos que envolvem os custos fixos inerentes a atividade. Qualificar os funcionários é obrigatoriedade do produtor, pois a atividade poderá alcançar os indicadores de produção desejados e cumprir as obrigações no que se refere a legislação brasileira e o pagamento dos tributos previstos em lei são premissas obrigatórias aos produtores que tem uma atividade legalizada e comercializam os produtos em locais supervisionados, não sendo estes considerados riscos que inviabilizem a atividade pecuária desenvolvida.

As composições dos custos de produção na criação de avestruz demonstraram que independente do sistema de gestão da atividade, o dispêndio de capital com a compra de ração concentrada (tabela IV) foi o item de maior expressão. Com $41 \%$ e $44 \%$ dos custos totais de produção, para o sistema que adotou incubatório próprio e terceirizado, respectivamente, os resultados obtidos corroboram com a assertiva de Bianco (2006) que afirmou ser a ração concentrada, a categoria de maior participação na composição dos custos totais na criação de avestruz, representando 45 \% dos custos totais de produção. Com a maior participação da matéria prima (ração concentrada) na composição dos custos de produção confirmou-se que a escassez do produto é uma preocupação dos respondentes para garantia do sucesso da criação. A falta deste insumo ou seu uso de forma errônea, sem o devido balanceamento pode comprometer o desempenho dos animais.

No sistema de criação de avestruz que adotou incubatório próprio, observou-se que os custos administrativos (tabela IV) foram a segunda categoria na escala

Tabela IV. Composição dos custos de produção da criação de avestruz, em \%, na condição de incubação dos ovos em incubatório próprio ou terceirizado (Production costs composition of the ostrich farm, in $\%$, for condition incubation of eggs on their own or outsourced hatchery).

\begin{tabular}{lcc}
\hline \multirow{2}{*}{ Categoria } & \multicolumn{2}{c}{ Incubatório } \\
\cline { 2 - 3 } & Próprio & Terceirizado \\
\hline Custos administrativos & $29 \%$ & $27 \%$ \\
Ração concentrada-Fase de engorda & $20 \%$ & $22 \%$ \\
Ração concentrada-Fase de cria & $13 \%$ & $14 \%$ \\
Incubação terceirizada & - & $9 \%$ \\
Mão de obra-Cria, recria e engorda & $11 \%$ & $6 \%$ \\
Mão de obra-Reprodutores e matrizes & $6 \%$ & $6 \%$ \\
Ração concentrada-Reprodutores e matrizes & $6 \%$ & $6 \%$ \\
Incubação própria & $6 \%$ & - \\
Assistência veterinária & $4 \%$ & $4 \%$ \\
Encargos trabalhistas & $3 \%$ & $2 \%$ \\
Ração concentrada-Fase de recria & $2 \%$ & $2 \%$ \\
Transporte de ovos para o incubatório & - & $2 \%$ \\
Total & $100 \%$ & $100 \%$ \\
\hline
\end{tabular}




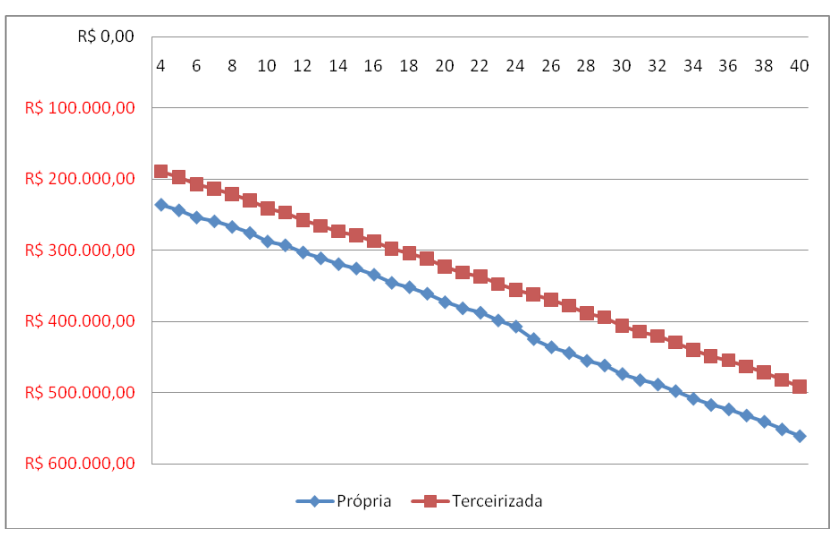

Figura IV. Investimento inicial, em $\mathrm{R} \$$, e casais reprodutores, em quantidades, necessários para implantação de uma criação de avestruzes com incubatório próprio ou terceirizado (Initial capital, in reais, and breeding pairs, in amounts, necessary to ostrich farm implantation with own or outsourced hatchery).

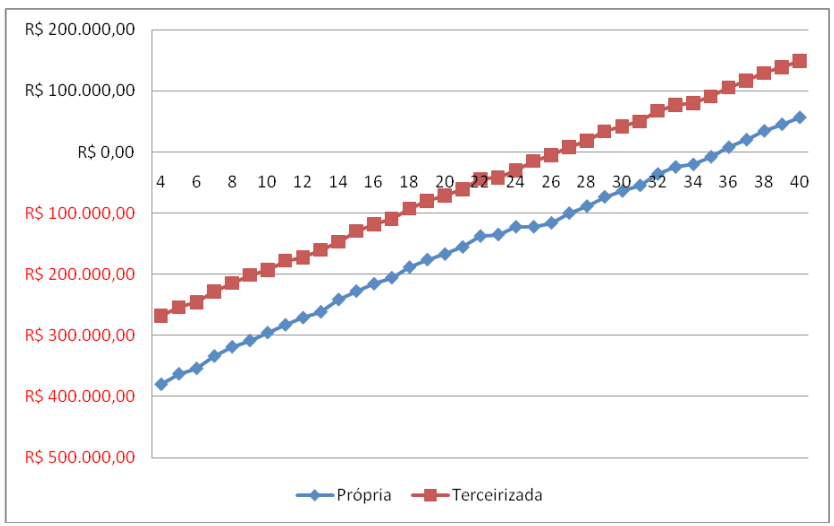

Figura V. Número de casais reprodutores que tornaram o VPL nulo, em R\$ (VPL= 0 ajustado ao risco e ao equivalente de certeza) (Number of breeding pairs for NPV null, in reais (NPV $=0$ adjusted for risk and certain equivalent)).

de importância, representando $29 \%$ dos custos totais de produção. Este valor representou os gastos mensais com a implantação e manutenção dos piquetes de criação (reparos de cercas, portões,... ), manutenção dos equipamentos (limpeza, custos com combustíveis,... ), implantação e manutenção das pastagens (aplicação de corretivos, fertilizantes,... ) e da infraestrutura da propriedade. Seguido pelos custos administrativos, identificou-se a mão de obra como o terceiro item na composição dos custos de produção (mão de obra contratada, assistência técnica,... ), representando $24 \%$. Já, os custos administrativos para o incubatório terceirizado corresponderam por $27 \%$ dos custos totais de produção, seguido pelos custos com a mão de obra que representaram $18 \%$, desconsiderando os custos envolvidos com a mão de obra necessária para manutenção do incubatório, que nesta situação teve o serviço de incubação dos ovos terceirizado. Giannoni (2002) ressaltou que na criação que adota o incubatório próprio, este pode ser considerado o mais importante segmento, já que exige diversas instalações como: salas para recepção, limpeza e estocagem dos ovos, salas para acondicionamento da incubadora e maternidade para os pintos de um dia, exigindo controle permanente de temperatura e umidade, enquanto que no sistema de produção que adota incubadora terceirizada de ovos, estas características são transferidas a uma empresa especializada.

O investimento inicial necessário para a implantação de uma criação de avestruzes que adotou incubatório próprio, independente do número de casais reprodutores foi maior que aquele necessário para uma criação com incubatório terceirizado (figura IV). $\mathrm{Na}$ criação de avestruzes, o número mínimo de casais reprodutores para que o VPL fosse positivo foi de $22 \mathrm{e}$ 17 (sem riscos) para a criação que adotou incubatório próprio e terceirizado, respectivamente. Considerando, o risco do investimento e o equivalente de certeza, o número mínimo necessário para que o NV fosse positivo passou para 36 casais na criação que adotou incubatório próprio, ao passo que, na criação que adotou incubatório terceirizado, o número mínimo para tornar o valor presente líquido positivo foi de 27 casais (figura V).

O tempo de recuperação do capital investido ( $p a-$ yback) estimado para uma criação de 36 casais reprodutores (incubatório próprio) foi de 9,8 anos, ao passo que, para a criação que adotou incubatório terceirizado o payback foi de 9,7 anos (27 casais reprodutores). O estudo demonstrou que a criação que adotou o incubatório terceirizado apresentou um retorno econômico mais rápido do capital investido. Em estudo realizado por Seolin (2004) foi observado que para implantação de uma estrutiocultura com 10 casais reprodutores, o tempo de recuperação do capital investido (payback) descontado a uma taxa de $12 \%$ ao ano foi de dois anos e a taxa interna de retorno do empreendimento estimada em $47 \%$ ao ano. Fabro (2007) observou que na implantação de uma estrutiocultura com cinco casais reprodutores, dois anos e onze meses foi o tempo necessário para recuperação do capital investido e, quando considerada uma taxa de desconto de $2 \%$ ao mês o payback descontado passaria para 3,2 anos. Para Hofer e Schultz (2007) em uma estrutiocultura instalada na região oeste do estado do Paraná, a viabilidade econômico-financeira deu-se com onze casais reprodutores. Os autores projetaram a ampliação da atividade, baseado no capital financeiro e na infraestrutura imobilizada sendo encontrada uma capacidade de instalação e exploração para 22 casais reprodutores. Os resultados observados não corroboram com as assertivas de Seolin (2004) e Fabro (2007) onde as autoras afirmaram que a estrutiocultura é um empreendimento em que a recuperação do capital investido é possível no curto prazo, fato este não constatado. A divergência entre os resultados obtidos para o payback foi explicada pela caracterização de cada sistema de produção, bem como a escala de produção considerada. Nos estudos de Seolin (2004) e Fabro (2007) não foram considerados os custos fixos e variáveis inerentes a incubação dos ovos, além disso, o total de casais reprodutores adquiridos para a exploração da atividade foram $10 \mathrm{e}$ 5 casais reprodutores, respectivamente. Neste trabalho, consideraram-se os custos envolvidos na incubação dos ovos a partir de incubatório próprio e incubatório terceirizado e o número mínimo de casais reprodutores para viabilizar economicamente a atividade foi de $36 \mathrm{e}$ 27 casais reprodutores, respectivamente, o que refletiu 
em um maior tempo de recuperação do capital investido, sendo concluído que o empreendimento requer um período de longo prazo para o produtor recuperar todo o investimento realizado.

Avaliando os dois fluxos de caixa foi possível compreender como o risco financeiro interferiu negativamente no fluxo do empreendimento, sendo extremamente importante o estudo do mesmo para uma decisão mais segura do investidor. A partir da análise comparativa dos resultados, foi possível a tomada de decisão de investimento mais precisa nas situações em que a criação adotou incubatório próprio ou terceirizado. Além disso, ressaltou-se a importância do investidor conhecer a cadeia produtiva da estrutiocultura na região em que se deseja produzir, pois ao escolher terceirizar o incubatório, este serviço deve ter pontualidade e qualidade genética na oferta de pintinhos, garantindo animais com elevado potencial genético e bons resultados zootécnicos.

Os resultados obtidos assemelharam-se às atuais práticas realizadas na cadeia produtiva da avicultura de corte, caracterizada pela criação de aves para produção de carne, a partir da aquisição de pintainhos de um dia, provenientes de incubatórios especializados na seleção de aves de alta produção (Costa, 2008). Em estudo realizado por Moore et al. (2014) sobre a vulnerabilidade da indústria sul africana de avestruzes frente a ocorrência de doenças e presença de patógenos na criação, o uso da análise de redes permitiu o fornecimento de informações úteis para o monitoramento e gerenciamento da atividade, garantindo maior qualidade nos produtos comercializados, bem como maior eficiência produtiva nos criatórios. Os resultados deste estudo corroboram com a assertiva dos autores, uma vez que a busca pela eficiência produtiva e garantia da qualidade dos animais produzidos por meio de uso de incubatório, melhoraram os resultados zootécnicos e a rentabilidade da criação, tornando a atividade mais atrativa para investimento. Segundo os autores, com o estudo realizado pela análise de redes foi possível identificar a vulnerabilidade das aves frente a principal doença analisada, a gripe aviária e recomendar o envio dos filhotes de avestruzes para fazendas de criação especializadas, minimizando assim o risco das aves frente a infecção causada pela doença.

A estrutiocultura pode ser uma alternativa viável para investidores que desejam produzir uma carne nobre (exótica) para atendimento de um mercado seletivo nos grandes centros urbanos. Nesta condição, é preciso que a cadeia produtiva da estrutiocultura seja estruturada, com fornecimento de animais com potencial genético para o ganho de peso, aliado ao estímulo e desenvolvimento do consumo desta carne pelos consumidores, promovendo assim, a verticalização da criação, recomendação esta identificada por Rodrigues e Macedo (2014).

\section{CONCLUSÕES}

Nos sistemas de criação analisados, os principais custos de produção são: alimentação concentrada (ração peletizada) e custo administrativo do empreendimento.

Para os cenários analisados são necessários 27 casais reprodutores para viabilizarem economicamente a implantação de uma estrutiocultura com incubadora terceirizada e 36 casais reprodutores para uma criação com incubatório próprio.

A criação de avestruz que adota a incubação terceirizada de ovos apresenta a composição dos custos totais de produção mais atrativa para investimento, menor risco financeiro e menor tempo de recuperação do capital investido.

\section{BIBLIOGRAFIA}

Associação Comercial de São Paulo - ACSP. 2015. Índices econômicos: média mensal da cotação do dólar comercial para venda, em real (R\$). http://portal.acsp.com.br/assets/html/indicadores/indicadores_iegv/iegv_dolar.html (07/12/2015).

Associação de Criadores de Avestruz do Brasil - ACAB. 2006. Anuário da estrutiocultura brasileira 2005/2006. $1^{a}$ ed. ACAB. São Paulo, SP.

Avicultura industrial. 2011. Estrutiocultura brasileira em busca de crescimento. http://www.aviculturaindustrial.com.br/noticia/ estrutiocultura-brasileira-em-busca-de-crescimento/201 103251316 58_J_915 (09/12/2015).

Barnes, J.I. e Jager, J.L.V. 1996. Economical and financial incentives for wildlife use on private land in Namibia and the implications for policy. S Afr J Wildl Res, 26: 237-246.

Bianco, P.P. 2006. A estrutura da cadeia do avestruz no Brasil: um estudo exploratório. Dissertação de Mestrado. Universidade Federal de São Carlos. 102 pp.

Blank, L. e Tarquin, A. 2008. Engenharia econômica. $6^{a}$ ed. McGrawHill. São Paulo. SP. 756 pp.

Egbe, B.O. 2015. Analysis of farm management skills of poultry production operators in Ebonyi state. J Educ Policy Entrepren Res, 2: 29-33.

Estes, G.M. e Kuespert, D. 1976. Delphi in industrial forecasting. Chem Eng News, 40-47.

Fabro, D.D.P. 2007 . Estudo de viabilidade econômica e financeira de uma empresa de criação e comercialização de avestruz e seus produtos. Monografia de Graduação em Administração. Universidade Federal de Santa Catarina. 99 pp.

Giannoni, M.L. 2002. Avestruz: reprodução, cria e recria. $1^{a}$ ed. Editora CPT. Viçosa. MG.

Harris, M. e Raviv, A. 1996. The capital budgeting process: incentives and information. J Financ, 51: 1139-1174.

Hofer, E. e Schultz, C.A. 2007. Estrutiocultura: uma alternativa para a pequena propriedade rural. In: VII Congresso USP Controladoria e Contabilidade. Universidade de São Paulo-USP. http://www.congressousp.fipecafi.org/web/artigos72007/677.pdf (22/10/2014).

Martino, J.P. 1993. Technological forecasting for decision making. $3^{a}$ ed. Editora McGraw-Hill Inc. São Paulo. SP.

Moore, C.; Cumming, G.S.; Slingsby, J. e Grewar, J. 2014. Tracking socioeconomic vulnerability using network analysis: insights from an avian influenza outbreak in an ostrich production network. http://journals.plos.org/plosone/article?id=10.1371/journal. pone. 0086973 (01/04/2015).

Muniz, L.R. 2006. Estatística censitária da estrutiocultura brasileira. Anuário da Estrutiocultura Brasileira. São Paulo. SP.

Nogueira, C.A. 2009. Análise de viabilidade econômico-financeira da criação de avestruz. Monografia de Graduação em Engenharia de Produção. Universidade Federal Fluminense. 74 pp.

Nogueira, C.A.; Brandalise, N.; Peres, A.A.C.; Portz, A.; Carneiro, C.A.G.V. e Silva, R.T. 2012. Composição dos custos de produção em sistemas de gestão na criação de avestruzes. In: $49^{\circ}$ Reunião Anual da Sociedade Brasileira de Zootecnia. Universidade de Brasília - UnB. 
Rodrigues, F.C. e Macedo, L.O.B. 2014. Análise da reestruturação da estrutiocultura brasileira após a crise de 2005-2007: um exame da tendência à verticalização dos segmentos de abate e comercialização. Inform Econ, 44: 37-49.

Seolin, F. 2004. Viabilidade econômico-financeira para a implantação da estrutiocultura no município de Presidente Prudente- SP. Monografia de Graduação em Ciências Econômicas. Faculdades Integradas Antônio Eufrásio de Toledo. 60 pp.
Silva, R.A. 2008. Análise da conjuntura agropecuária - safra 2008/09: estrutiocultura. Boletim técnico. Curitiba. PR. http://www.agricultura. pr.gov.br/arquivos/File/deral/Prognosticos/estrutiocultura_0809. $\operatorname{pdf}(09 / 12 / 2015)$.

Skulmoski, G.J.; Hartman, F.T. e Krahn, J. 2007. The Delphi method for graduate research. J Inform Technol Educ, 6: 1-21.

Suzan, E. e Gameiro, A.H. 2007. Perspectivas e desafios do sistema agroindustrial do avestruz no Brasil. Inform Econ, 37: 44-59. 